\title{
Prevalence of Styloid Process Elongation in An Elderly Turkish Population
}

\author{
Melek Tassoker, Sevgi Ozcan \\ Department Of Oral And Maxillofacial Radiology, Necmettin Erbakan University, Turkey
}

\begin{abstract}
The styloid process is a cylindrical, long cartilaginous bone located on the temporal bone. The styloid process elongation can be assumed when either the styloid process or the adjacent stylohyoid ligament ossification shows an overall length greater than $30 \mathrm{~mm}$. The purpose of this study was to obtain data for the prevalence of elongated styloid process in an elderly Turkish population. The study sample consisted of orthopantomographs of 100 subjects, aged between 65-90 years. 38 subjects (38\%) demonstrated styloid process elongation at least one side. This study has been showed that elongated styloid process is a common radiological finding in elderly people.
\end{abstract}

Keywords: styloid process, stylohyoid ligament, elongation, elderly.

\section{Introduction}

The styloid process (SP), which is derived from the Reichert's cartilage of the second branchial arch, is a cylindrical bony projection, of approximately 20 to $30 \mathrm{~mm}$ in length, located in the temporal bone, immediately in front of the stylomastoid foramen [1]. The tip of the SP is continuous with the stylohyoid ligament, which extends to the lesser cornu of the hyoid bone [2]. The styloid process elongation can be assumed when either the styloid process or the adjacent stylohyoid ligament ossification shows an overall length greater than $30 \mathrm{~mm}$ [3]. The elongation of SP or ossification of stylohyoid ligament can cause to Eagle's syndrome [4]. The syndrome characterized by neck and cervicofacial pain and uncommonly sypmtoms such as dysphagia, tinnitus, and otalgia [2]. It is crucial for the dentists, otolaryngologists and neurologists to be aware of the elongation of the SP and its anatomical basis [5].

Eagle's syndrome is diagnosed by both radiographical and physical examination. The SP palpation in the tonsillar fossa is indicative of elongated SP which are not normally palpable. Palpation of the tip of the SP should exacerbate existing symptoms [3]. If any of the symptoms exist, digital palpation of the SP as a simple diagnostic procedure should be routine during the examination [5].

Panoramic radiography is the most common projection to detect an elongated SP [5]. The purpose of this study was to determine the prevalence of elongated styloid process using digital panoramic radiographs in an elderly Turkish population.

\section{Mater $\square$ al and methods}

The study sample consisted of orthopantomographs (OPG) of 100 subjects, aged 65-90 years (44 males and 56 females) who attended our university clinic for an initial visit between 2014-2015 years. Each subject had an OPG taken as part of the routine examination. OPGs of the patients were taken under standart exposure factors, as recommended by the manufacturer. $\left(68 \mathrm{kVp}, 10 \mathrm{~mA}\right.$, with digital OPG machines-Kodak ${ }^{\circledR} 8000$, Rochester, New York, USA). The apparent length of the styloid process was measured by using Adobe® Photoshop ${ }^{\circledR}$ CS4 version 11.0 with a magnification factor of 1,27 . The length of SP was measured in a similar way described by Jung et al (2004) [6] (Figure 1,2). Styloid process measuring more than $30 \mathrm{~mm}$ were considered as elongated.

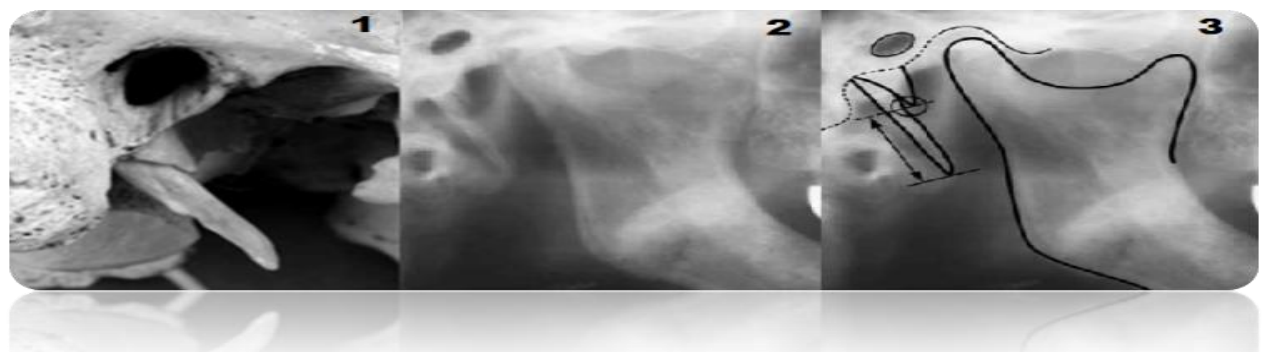

Figure 1. 1. Cleft between the lower margin of the tympanic plate of the temporal bone and the styloid process, on a dry skull, mandible not in place. 2. Cleft between tympanic plate and styloid process, seen on 
panoramic radiograph as a slit. 3 . The circle shows the origin for measurements and the length of the arrow corresponds with the length of the styloid process on the panoramic radiographs.

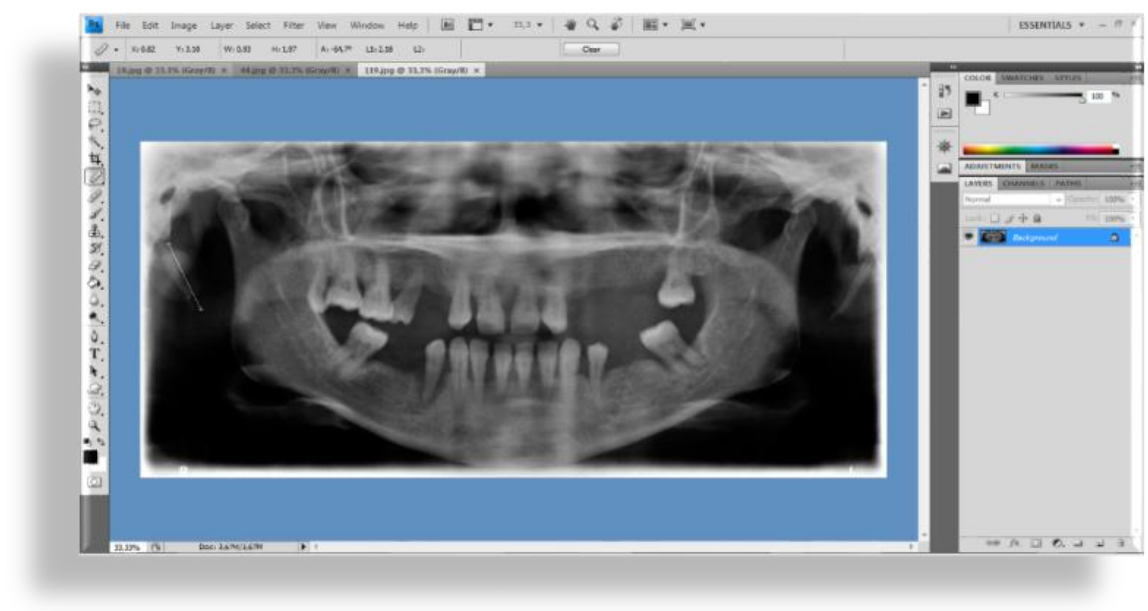

Figure 2. The apparent length of the styloid process was measured by using Adobe ${ }^{\circledR}$ Photoshop ${ }^{\circledR}$ CS4 version 11.0 (with a magnification factor of 1,27 ).

Table 1. Elongated SP studies in the literature

\begin{tabular}{|llll|}
\hline Year & Authors & Sample Size & Prevalence (\%) \\
\hline 1970 & Kaufman [7] & 484 & 28 \\
\hline 1979 & Correll et al. [8] & 1771 & 18,2 \\
\hline 1984 & O'Carroll [9] & 479 & 78,5 \\
\hline 1986 & Monsour and Young [10] & 670 & 21,1 \\
\hline 1990 & Ferrairo et al. [11] & 286 & 84,4 \\
\hline 1991 & Rath and Anand [12] & 232 & 0,4 \\
\hline 2009 & Balcioglu [13] & 227 & 3,3 \\
\hline 2010 & More and Asrani [14] & 500 & 19,4 \\
\hline 2012 & Bagga et al. [2] & 2706 & 52,1 \\
\hline 2015 & Marçal Vieira et al. [1] & 736 & 43,89 \\
\hline
\end{tabular}

The observed results were analyzed by using SPSS 21.0 (statistical package for social science Inc. Chicago, USA). Data were analyzed using descriptive statistics and chi-squared test with a significant level at $\mathrm{p}<0,05$.

\section{Results}

38 subjects (38\%) demonstrated styloid process elongation at least one side. Out of the 100 panoramic radiographs (200 styloid processes), $29(76,3 \%)$ showed bilateral elongation and $9(23,7 \%)$ showed unilateral elongation. There was no significant difference in styloid process elongation between two genders $(p>0,05)$.

\section{IV. $\quad$ D $\square$ scuss $\square$ on}

The morphological characteristics of the SP have been studied by several researchers (Table 1) using different methodologies, including dried skull, panoramic radiographs as we did, computed tomography (CT) and cone beam computed tomography (CBCT) [1]. The results of the studies shows that the prevalence of SP elongation varies between $0,4-84,4 \%$ of the population. Our result $(38 \%)$ is in accordance with the literature. Different results could be due to differences in the selected age structure and sample size. Thus, comparing the results of the prevalence of elongated SP is impossible because of ethnical, racial and anatomical variations, differences in radiographic devices and differences observers [15].

Panoramic radiograph has been shown to be a suitable tool for epidemiological studies [1] but accurate determination using two-dimensional radiographic procedures can be difficult due to projection geometry considerations such as magnification and distortion of the SP [2]. CT and CBCT provides reliable threedimensional visualizaton of these structures but they cause higher radiation exposure to the individual. On the other hand, if a surgery is planned on the SP area, three dimensional imaging techniques should be used.

Elongation of the SP is often asymptomatic, and its pathogenesis is still unknown [15]. Various theories have been suggested to explain the elongation of the SP and ossification of the stylohyoid ligament, namely the theory of reactive metaplasia, reactive hyperplasia, anatomic variance, ageing, developmental anomaly, and trauma leading to loss of elasticity in the stylohyoid ligament [2]. According to our results SP elongation is common in elderly people probably because of the calcification of the stylohyoid ligament with 
aging. Regarding gender, no statistically significant difference was observed between genders in the unilateral or bilateral elongation of the SP. This was in agreement with the previous studies $[11,15,16]$.

\section{Conclusion}

This study provides an epidemiological data about elongated styloid process in an elderly Turkish population. Elongation of styloid process in elderly people is common with no correlation to gender.

\section{References}

[1]. Marçal Vieira EM, Guedes OA, De Morais S, De Musis CR, De Albuquerque PAA et al. Prevalence of elongated styloid process in a central Brazilian population. J Clin Diagn Res 2015; 9: ZC90-ZC92.

[2]. Bagga MB, Kumar CA, Yeluri G. Clinicoradiologic evaluation of styloid process calcification. Imaging Science in Dentistry. 2012; 42:155-61.

[3]. Gokce C, Sisman Y, Sipahioğlu M. Styloid process elongation or Eagle's syndrome: Is there any role for ectopic calcification? Eur J of Dent. 2008; 2:224-228.

[4]. Shaik MA, Kaleem M, Wahab A, Hameed S. Prevalance of elongated styloid process in Saudi population of Aseer region. Eur J Dent. 2013: 7:449-54

[5]. Balcioglu HA, Kilic C, Akyol M, Ozan H, Kokten G. Length of the styloid process and anatomical implications for Eagle's syndrome. Folia Morphol. 2009; 68:265-270.

[6]. Jung T, Tschernitschek H, Hippen H, Schneider B, Borchers L. Elongated styloid process: when is it really elongated? Dentomaxillofacial Radiology. 2004; 33:119-124.

[7]. Kaufman SM, Elzay RP, Irish EF. Styloid process variation. Radiologic and clinical study. Arch Otolaryngol. 1970; 91:460-3.

[8]. Correll RW, Jensen JL, Taylor JB, Rhyne RR. Mineralization of the stylohyoid-stylomandibular ligament complex. Oral Surg. $1979 ; 48: 286-291$.

[9]. O’Carroll MKO. Calcification in the stylohyoid ligament. Oral Surg. 1984; 58:617-621.

[10]. Monsour PA, Young WG. Variability of the styloid process and stylohyoid ligament in panoramic radiographs. Oral Surg Oral Med Oral Pathol. 1986; 61:522-526.

[11]. Ferrairo VF, Sigurta D, Daddona A, Dalloca L, Miani A, Tafuro F, Sforza C. Calcification of the stylohyoid ligament: Incidence and morphoquantitative evaluations. Oral Surg Oral Med Oral Pathol. 1990; 69:520-9.

[12]. Rath G, Anand C. Abnormal styloid process in a human skull. Surg Radiol Anat 1991; 13:227-229.

[13]. Balcioglu HA, Kilic C, Akyol M, Ozan H, Kokten G. Length of the styloid process and anatomical implications for Eagle's syndrome. Folia Morphol. 2009; 68:265-270.

[14]. More CB, Asrani MK. Evaluation of the styloid process on digital panoramic radiographs. Indian Journal of Radiology and Imaging. 2010; 20:261-265.

[15]. Shakibaei Z, Tohidi E, Salemi F, Saati S. Prevalence of Stylohyoid Ligament Calcification on Panoramic Radiographs in an Iranian Population. JDMT 2015; 4:21-28.

[16]. Ilguy M, Ilguy D, Güler N, Bayirli G. Incidence of the type and calcification patterns in patients with elongated styloid process. The Journalof International Medical Research. 2005; 33:96-102. 